\title{
Fatores de influência na presença do pronome clítico em função de objeto: semântica verbal e gênero textual
}

\section{Significant factors in the use of clitic object pronouns: verb semantics and genre}

Victor Araujo Coutinho1, Orlene Lúcia de Saboia Carvalho²

Mesre, professor visitante no departamento de Latin American and Iberian Cultures da Columbia do projeto de pesquisu "Lingústica e participante Ensino de Língua Estrangeira: Colocações Lexiçis no corpus Banco Brasileiro e nos Livros Didáticos de Português Brasileiro", financiado pelo CNPq. E-mail: araujo.vct@gmail.com

Doutora, professora associada no Programa de Pos-Graduaçăo em Linguística da Universidade Segunda Lingua/língua Estrangera Lrasicomo Lexicografia Coordenadora do projeto de pesquisa "Linguística de Corpus e Ensino de Língua Estrangeira: Colocaçōes Lexicais no corpus Banco Brasileiro e nos Livros Didáticos de Português

E-mail: orlone saboia@unb br
RESUMO: Este estudo se dedica a analisar o fenômeno de variação da explicitação do pronome objeto direto em situação de anáfora textual no português brasileiro. Atualmente, pode-se retomar anaforicamente um elemento em função de objeto direto por meio do emprego de itens lexicais de clíticos, dos pronomes ele(s)/ela(s), ou pode-se deixar a posição vazia, sem retomada explícita (BAGNO, 2013: 471). Neste cenário, nos dedicamos a investigar que traços semânticos e pragmático-discursivos interferem na escolha entre a presença ou não do pronome objeto, em textos escritos. Para tanto, tomamos como base teórica os parâmetros concernentes à transitividade verbal, propostos por Hopper e Thompson (1980) e retomados por Cunha e Sousa (2011) em análise do português brasileiro, e a noção de gênero textual de Marcuschi (2003, 2008). Metodologicamente usamos as ferramentas da Linguística de Corpus. Levantamos dados no corpus Brasileiro, que registra mais de 1,1 bilhão de ocorrências, e realizamos análises de natureza quantitativa e qualitativa com base em Tarallo (1986) e Sardinha (2004). Os resultados revelaram que o traço semântico verbal "afetamento do objeto", bem como a ocorrência em gêneros textuais mais formais atuam como fatores condicionantes na explicitação do pronome objeto. PalaVRaS-CHAVE: Variação; Pronomes Objeto; Semântica; Gêneros.

ABSTRACT: This article analyses variation in the use of the object pronouns in the context of anaphora in Brazilian Portuguese. Nowadays, it is possible to retake direct object through anaphora by means of using a noun phrase, clitic pronouns, the pronouns "ele(s)/ela(s)", or by having zero anaphora (BAGNO, 2013, p. 471). In this scenario, we have studied the role of semantic, pragmatic-discursive factors that interfere in the choice between using the object pronoun or not. As a theoretical approach, we took the parameters concerning the transitivity of verbs, proposed by Hopper e Thompson (1980) and used by Cunha e Sousa (2011) in the analysis of Brazilian Portuguese, and the notion of genre by Marcuschi (2003, 2008). Methodologically we used the tools from Corpus Linguistics. We collected our data in the corpus Brasileiro, which registers more than one billion tokens, and analysed our data quantitavely and qualitatively. The results revealed that the verb semantic trace "affectedness of 0 ", as well as the formal genres act as determining factors in the use an object pronoun.

KEYwoRDS: Variation; Object Pronouns; Semantics; Genres. 


\section{Introdução}

$\mathrm{N}$

as últimas décadas, estudos sobre variação linguística têm demonstrado como se configura, de fato, o português brasileiro (PB). Sabe-se, há muito, que o sistema linguístico varia em suas estruturas morfossintáticas, não se restringindo a variantes lexicais como "macaxeira", "mandioca" e "aipim" - lamentavelmente as atividades do eixo de conhecimentos linguísticos dos livros didáticos raramente ultrapassam a fronteira lexical -, apesar de a variação lexical ser um forte traço marcador das regiões brasileiras. Intervêm nos fenômenos de variação fatores extralinguísticos diversos, como a origem geográfica, os contextos sociais, o status socioeconômico, o grau de escolarização, as gerações e o sexo de falantes nativos, além das redes sociais a que pertencem (BAGNO, 2001, 2007).

No contexto de variação linguística do PB, para a construção deste artigo, selecionamos um dos fenômenos que evidencia a distância existente entre a sistematização normativa, encontrada em gramáticas tradicionais e livros didáticos de português como L1 e como L2, e a realidade linguística do português brasileiro (PB), a retomada anafórica de $3^{\underline{a}}$ pessoa em função de objeto.

As sistematizações propostas pelas gramaticas normativas, que se limitam a contemplar os clíticos, divergem muito das regras que são realmente utilizadas pelos falantes do PB. Atualmente há quatro possíveis estratégias para se retomar um objeto direto.

Para a pergunta "Você entregou o relatório ontem?", podemos obter as seguintes respostas:

1) “Não, mas vou entregar $\varnothing$ amanhã" (sintagma expresso por pronome nulo);
2) “Não, mas vou entregar ele amanhã" (sintagma com núcleo pronominal: pronome pessoal tônico reto de $3^{\text {a }}$ pessoa);

3) "Não, mas vou entregá-lo amanhã" (sintagma com núcleo pronominal: pronome pessoal oblíquo átono de 3 a pessoa); e

4) “Não, mas vou entregar o relatório amanhã" (sintagma com repetição do núcleo nominal).

De acordo com pesquisa levantada por Duarte (1986) e sistematizada por Bagno (2013) em tabela comparativa (ver Tabela 1), o PB contemporâneo apresenta uma forte tendência de deixar a posição de objeto vazia. Veja-se que o percentual referente à ausência de pronome é consideravelmente maior do que a soma de todas as outras estratégias em que o objeto direto (OD) aparece explicitamente na estrutura da frase.

Tabela 1 - Variação no emprego de estratégias de retomada anafórica

\begin{tabular}{|c|c|c|c|c|c|}
\hline \multicolumn{3}{|c|}{ Duarte (1989, p. 21) } & \multicolumn{3}{|c|}{ Bagno (2013, p. 470-471) } \\
\hline Variante & № & $\%$ & Variante & № & $\%$ \\
\hline Pronome clítico & 97 & 4,9 & Pronome Clítico & 3 & 0,6 \\
\hline Pronome reto & 304 & 15,4 & Pronome Reto & 18 & 3,6 \\
\hline Pronome nulo & 1235 & 62,6 & Pronome Nulo & 479 & 95,8 \\
\hline SN anafórico & 338 & 16,1 & SN anafórico & 0 & 0 \\
\hline Total & 1974 & 100,0 & Total & 500 & 100,0 \\
\hline
\end{tabular}

É importante mencionar a constatação de Tarallo (1993) de que existe uma correlação histórica entre o percentual das ocorrências do pronome nulo e o da explicitação obrigatória do sujeito, conforme ilustra o Gráfico 1 a seguir: 
Gráfico 1 - Explicitação de Sujeitos e Objetos no PB

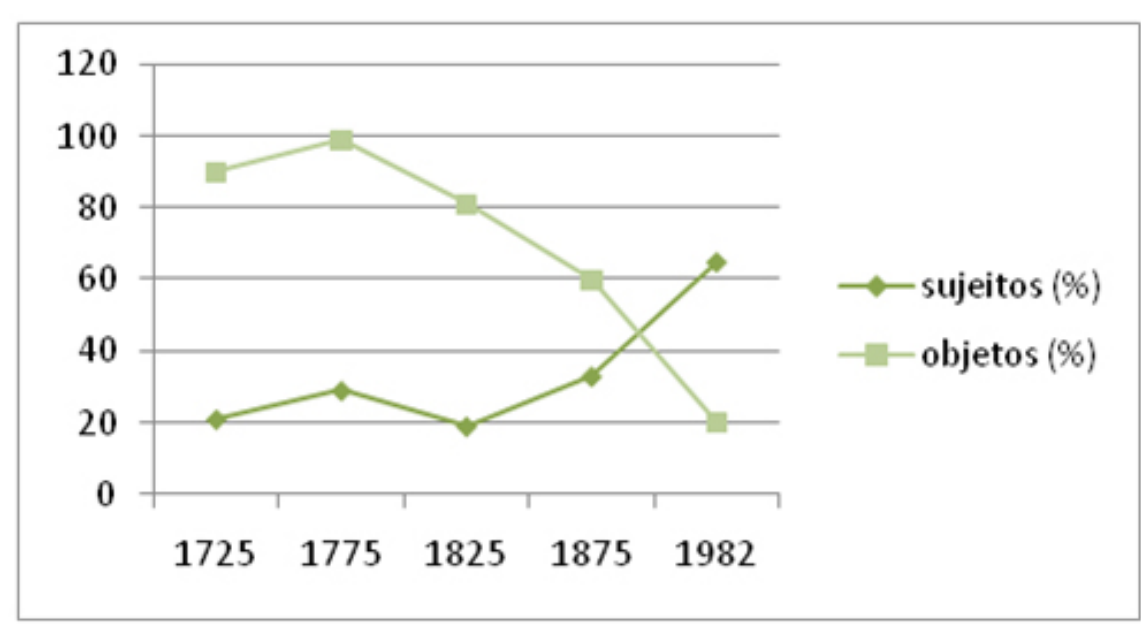

Fonte: Tarallo (1993, p. 72)

Este gráfico retrata os resultados do estudo de um corpus que compila 250 anos de textos escritos. É possível perceber que, nos cinquenta anos que antecederam à década de 1980, a explicitação do sujeito foi se tornando cada vez mais frequente - devido sobretudo à redução das formas verbais com a introdução dos pronomes você, vocês e a gente. Em contrapartida, o objeto foi ficando cada vez mais apagado, sendo reduzido de maneira simétrica à explicitação do sujeito. Note-se que o aumento de percentual de apagamento do objeto nesse gráfico complementa as informações do quadro comparativo de Bagno, sendo evidente a mudança em 250 anos de língua escrita, assim como a mudança na oralidade dos falantes nativos de PB.

No que diz respeito ao estágio atual da língua, o que move esta pesquisa não se restringe apenas à constatação de que há diferentes formas de retomada do objeto direto no discurso. Entendemos que cada forma na língua tem uma função distinta, que não existem sinônimos perfeitos, intercambiáveis sem alteração no significado (ILARI, 2001) e que alterações estruturais em enunciados, como no caso da colocação pronominal, diferem em termos de "valor sociossimbólico" (BORTONI-RICARDO, 2014, p. 75).

Nossa hipótese é a de que traços semânticos verbais, bem como o grau de formalidade do gênero textual são fatores condicionantes do fenômeno variável, i. e., da seleção da estratégia de explicitação do pronome clítico na função de objeto. Estamos em busca de elementos que justifiquem a permanência dessa estratégia diante de um panorama de predominância da omissão. Sabemos que outros fatores também intervêm nesse processo. Koch (1997), por exemplo, demonstra que a distância entre o objeto retomado e o pronome favorece a explicitação do pronome objeto, já que, quanto mais distante, mais difícil fica para o leitor resgatar o substantivo ou a expressão inicial. Por este viés, Travaglia $(1991,2003)$ se dedica a observar os verbos a partir de seus sentidos e funções no texto. $\mathrm{O}$ autor relaciona os tipos de verbos (lexicais e gramaticais) aos tipos de situações (estáticas e dinâmicas) e propõe uma leitura dos verbos de acordo com suas características pragmático-discursivas. Essas perspectivas, no entanto, em que pesem suas relevâncias, não serão abordadas neste artigo. Isso porque a análise exposta neste artigo considera os traços semânticos internos do verbo a fim de compreender a extensão de sua influência na explicitação do pronome clítico.

Para a realização desta pesquisa, consideramos diferentes tipologias e classificações de verbos. É importante ressaltar que partimos do viés funcionalista tipológico, visto que este arcabouço teórico contempla tanto a estrutura (fonologia, morfologia e sintaxe) quanto o uso (semântica, pragmática e discurso). Portanto, partimos do arcabouço teórico proposto por Hopper e Thompson (1980), retomado por Cunha e Sousa (2011) para a análise do $\mathrm{PB}$, que contempla os traços que definem a transitividade verbal. Para a seleção dos verbos e o levantamento das ocorrências dos 
pronomes objeto, fazemos uso da metodologia da Linguística de Corpus (SARDINHA, 2004).

\section{Pesquisa sociolinguística}

Antes de discutirmos sobre os fatores que guiaram esta pesquisa, é importante ressaltar alguns aspectos da sociolinguística, área em que se insere este estudo. Tarallo (1986) define que a sociolinguística tem como premissa básica o entendimento da língua como um veículo de "comunicação, de informação e de expressão entre os indivíduos da espécie humana" (op. cit., p. 7). Desse modo, a sociolinguística não exclui o componente social dos elementos necessários para a realização de pesquisa acerca de fenômenos linguísticos, mas, sim, entende que os contextos sociais são fatores determinantes na análise de tais fenômenos.

Esta teoria foi impulsionada pelo icônico estudo do linguista William Labov sobre as influências sociais na variedade dialetal de Martha's Vineyard, resultando no artigo The social motivation of a sound change, de 1963. A partir de então, uma série de estudos foram produzidos a fim de compreender a heterogeneidade da língua e seus ambientes de variação. Estes estudos tinham como princípio a descrição dos fenômenos de variação de acordo com os diferentes contextos sociais em que aconteciam. E para que pudessem descrevê-los adequadamente, se basearam em um método que hoje compreendemos como "quantitativo" e "qualitativo".

A pesquisa quantitativa em sociolinguística exerce papel fundamental na medida em que evidencia em dados concretos um panorama da frequência do uso de determinadas formas. Com um forte apoio da Informática, atualmente é possível não só descrever as ocorrências, como também se pode compreender os padrões da língua, entendendo os condicionantes linguísticos, isto é, os elementos internos da língua que condicionam o uso (ex.: traços semânticos, papéis semânticos, estrutura sintática, etc.). 0 avanço tecnológico permitiu o desenvolvimento de ferramentas capazes de analisar uma grande quantidade de dados, o que até $1967^{1}$ era inimaginável. O crescimento deste campo impulsionou a Linguística de Corpus ${ }^{2}$, cuja metodologia de pesquisa foi aplicada no desenvolvimento deste artigo.

Por outro lado, os dados podem também ser levados a uma compreensão ainda mais profunda quando nos dedicamos a observar seu valor qualitativo. Por análise qualitativa, entendemos a dedicação dos pesquisadores em interpretar os valores obtidos quantitativamente, descrevendo os contextos de ocorrência das variantes encontradas e buscando os fatores e elementos que condicionam o fenômeno de variação em estudo. Assim, com o objetivo de obter uma ampla compreensão do fenômeno, os pesquisadores podem seguir dois caminhos de análise. A primeira, baseada na interpretação dos elementos extralinguísticos, isto é, dos fatores sociais que condicionam o uso da língua (ex: formalidade, localização geográfica, escolaridade, etc.). A segunda, voltada para os contextos de ocorrência, observando os fatores condicionantes dos elementos linguísticos inseridos nas práticas sociais, como é o caso do gênero textual, por exemplo.

Portanto, nos encontramos frente a duas análises vitais para a realização de pesquisa sociolinguística. A quantidade e a estatística dos dados são ferramentas tão importantes quanto a compreensão qualitativa dos mesmos. Ambas as análises se sustentam como base para que qualquer estudo sociolinguístico seja elaborado, a fim de se ampliar o conhecimento a respeito dos fenômenos pesquisados. Nesta pesquisa não é diferente, analisamos a explicitação do clítico como OD por ambos os pontos de vista e aqui descrevemos os resultados obtidos.

${ }^{1}$ Data de Publicação do estudo Computational Analysis of Present-Day American English por H. Kučera e W. N. Francis.

2 Ver sessão 3. 


\section{Transitividade verbal}

A fundamentação da análise qualitativa na interpretação do papel da transitividade verbal segue a vertente teórica funcionalista tipológica, que entende a língua como um sistema de pareamento entre forma e função (BYBEE, 1985; DIK, 1997; PAYNE, 1997), em especial os parâmetros de Hopper e Thompson (1980). E, para se compreender o que leva um falante a omitir ou explicitar o objeto direto, primeiro é preciso entender o que é, prototipicamente, o objeto direto (ROSCH, 1973).

No agrupamento de papéis sintático-semânticos em que atribuímos os valores de $\mathrm{S}$, A e P para os constituintes de uma oração, S é o sujeito único de uma oração cujo verbo é intransitivo, A, o sujeito de uma oração cujo verbo é transitivo, e P, o objeto de uma oração cujo verbo é transitivo (PAYNE, 1997).

Em português, teríamos:

1. Eu cheguei

(S)

2. Eu entreguei o relatório.

Desse modo, compreende-se que o objeto desta pesquisa assume, com base nas relações gramaticais e na prototipicidade, o papel de $\mathrm{P}$, já que tende a ser semanticamente o paciente da oração, enquanto sintaticamente se comporta como objeto direto do verbo. A partir desse viés, cabe a pergunta: Quais são os motivos que levam o falante a omitir o valor de P no discurso?

Em sua função prototípica, o verbo encerra traços semânticos os mais diversos (ROSCH, 1975). Além de guardar a semântica de uma ação processual sobre um objeto e definir a transitividade, suas flexões também são responsáveis por carregar informações de tempo, modo e aspecto da ação executada, de modo a deixar a comunicação extremamente precisa.

A proposta de Hopper e Thompson (1980: 252), retomada por Cunha e Sousa (2011: 47) 3 em análise do português, estabelece parâmetros que nos permitem mapear o valor da transitividade verbal e traçar um continuum entre os verbos de alta transitividade (AT) e de baixa transitividade (BT):

1. Número de participantes: um participante (BT) e mais de um participante (AT);

2. Cinese: verbo de não-movimento (BT) e verbo de movimento (AT);

3. Aspecto do verbo: não-perfectivo (BT) e perfectivo (AT);

4. Pontualidade do verbo: não-pontual (BT) e pontual (AT);

5. Intencionalidade do sujeito: ação não-intencional (BT) e ação intencional (AT);

6. Polaridade da ação: negativa (BT) e afirmativa (AT);

7. Modalidade da oração: modo irrealis (BT) e modo realis (AT);

8. Agentividade do sujeito: não-agentivo (BT) e agentivo (AT);

9. Afetamento do objeto: não-afetado (BT) e afetado (AT)

10.Individuação do objeto: não-individuado (BT) e individuado (AT)

Desses parâmetros, como o que está em questão é a presença ou a omissão do objeto direto em contexto de retomada anafórica, o que mais concerne a esta pesquisa é o afetamento do objeto, ou seja, há uma correlação de condicionamento entre o grau de afetamento do objeto, objeto não-afetado (BT) e afetado (AT), e a presença ou ausência do pronome objeto.

3 Estamos nos referindo à obra de Cunha e Sousa (2011) por usarmos as traduções por elas propostas. Assim, empregamos o termo "afetamento do objeto", em lugar de "afetação do objeto", como propõem outros autores. 
A seguir, discorreremos sobre a metodologia adotada e sobre os resultados obtidos.

\section{Coleta de dados: ferramentas da Linguística de Corpus}

Na coleta dos dados de referência para a análise, utilizamos a metodologia da Linguística de Corpus, que compreende a língua como um sistema de probabilidades (SARDINHA, 2004). Os dados foram extraídos do corpus Brasileiro, que atualmente registra mais de 1,1 bilhão de ocorrências e está hospedado no Sketch Engine, um programa on-line com corpora de várias línguas (https://www.sketchengine.co.uk). Esse corpus é constituído por variados gêneros textuais autênticos, o que garante uma análise estatística fidedigna para o levantamento das ocorrências, pois se trata do português brasileiro em uso.

Uma das ferramentas fornecidas pelo Sketch Engine permite o levantamento de colocações, com base em medidas de significância, como o LogDice, o Escore-T e a Informação Mútua, que indicam graus de probabilidade de associação entre duas palavras, considerando a frequência das palavras associadas ${ }^{4}$. Apesar de as colocações serem combinações compostas por itens lexicais (TAGNIN, 2013. p. 63; SARDINHA, 2004, p. 110), como o programa inclui pronomes no levantamento de colocações, assim como preposições, fizemos uso dessa ferramenta. Por exemplo, o verbo gostar (em todas suas flexões) ${ }^{5}$ e a preposição de têm $73.33 \%$ de chances de aparecerem justapostos, de acordo com o Brasileiro (além da preposição de, gostar pode ser colocado com vários advérbios de intensidade).

Como no sistema do Sketch Engine não é possível verificar os vazios lexicais com funções sintáticas, no caso, os pronomes nulos, nem os sintagmas

${ }^{4}$ Maiores detalhes sobre essas medidas de significância se encontram em Sardinha (2004: 200-206).
5 Dados obtidos por meio da busca de "gost*" no corpus, que abrange a raiz e todas as suas derivaçóes e flexões. nominais anafóricos, restringimos a pesquisa à ocorrência dos clíticos de 3 a pessoa $o(s), n o(s), l o(s)$ e $a(s), n a(s), l a(s)$ em função de OD

Por meio do programa Sketch Engine, coletamos os verbos que mais frequentemente ocorrem justapostos aos pronomes clíticos de 3 a pessoa em função de OD. A ferramenta realiza um cálculo estatístico, analisando o número de ocorrências conjuntas de dois itens (no caso, entre um verbo e um pronome clítico) em relação ao número total de entradas de cada item no corpus. Nesse cálculo, a ferramenta oferece não só o quantitativo de ocorrências registradas, mas também a probabilidade destes elementos ocorrerem justapostos.

Um dos números obtidos neste cálculo é chamado de Escore-T e serve justamente para separarmos ocorrências eventuais e aleatórias das ocorrências que demonstram um real padrão de uso da língua. Para que a combinação de dois itens seja tomada como um padrão, o Escore-T precisa ter um valor maior que 2 .

Sendo assim, coletamos uma lista com 62 verbos, ou lemas (aqui incluídas todas as conjugações), que ocorrem justapostos aos pronomes clíticos de 3 a pessoa em função de OD. Para chegar a esse quantitativo, consideramos apenas aqueles que tinham o Escore-T superior a 2, desconsiderando assim usos eventuais de verbos incomuns para analisar a real tendência do uso da língua. Em relação à posição do pronome clítico, consideramos todas válidas, contabilizando não apenas os pronomes em ênclise, mas também os pronomes em próclise e mesóclise.

\section{Análise de dados}

\subsection{Semântica lexical}

Dos 62 verbos obtidos, selecionamos uma amostra de sete verbos, entre os quais estão os três com maior número de ocorrências com clíticos e os 
quatro com menor número. No quadro abaixo, apresentamos o verbo na forma infinitiva (ou lema), o número de ocorrências com OD explícito por meio de pronominalização, o Escore-T, que demonstra que tais ocorrências não são aleatórias, além do percentual de ocorrências do verbo, em um total de 1.058 ocorrências de clíticos (ver Tabela 2).

Tabela 2 - Verbos e clíticos no corpus Brasileiro

\begin{tabular}{lccc}
\hline Verbo & $\begin{array}{c}\text { Ocorrências com } \\
\text { pronome OD }\end{array}$ & $\begin{array}{c}\text { Percentual de } \\
\text { ocorrências }\end{array}$ & Escore-T (>2) \\
\hline Fazer & 246 & 23,25 & 15,874 \\
Tornar & 42 & 3,96 & 6,474 \\
Utilizar & 30 & 2,83 & 5,477 \\
Apresentar & 7 & 0,66 & 2,646 \\
Ignorar & 7 & 0,66 & 2,644 \\
Preservar & 7 & 0,66 & 2,642 \\
Receber & 7 & 0,66 & 2,641 \\
Total & $346 / 1.058$ & - & - \\
\hline
\end{tabular}

Como podemos observar, verbos como fazer, tornar e utilizar, quando comparados com apresentar, ignorar, preservar e receber, apresentam uma maior tendência à explicitação do objeto, já que este sofre uma ação mais transformadora do verbo. Consequentemente, com verbos que não levam a uma mudança no estado do objeto, como é o caso de preservar e receber, são utilizadas outras estratégias de retomada anafórica ao invés de se empregar um pronome para retomá-lo.

Ao falarmos da semântica lexical do verbo, estamos olhando para os traços prototípicos e para os significados intrínsecos. No caso do verbo fazer, seu significado afeta diretamente o elemento em posição de objeto direto (P), podendo até mesmo ser a ação que o cria, conforme acepção do Dicionário Eletrônico Houaiss (2009): "produzir através de determinada ação”. O verbo tornar, por sua vez, implica um objeto cujas características transitam de um estado $x$ para um estado $y$ (HOUAISS, 2009), de modo que o objeto direto do verbo é profundamente afetado por sua semântica. Também é possível afirmar que o verbo preservar, cuja semântica lexical é de manutenção do estado de algo, ou seja, oposta à do verbo tornar, mantém as características do objeto intactas ao longo da ação-processo (BORBA, 1990).

Apresentamos a seguir alguns exemplos de textos colhidos do corpus analisado, como intuito de ilustrar a começar por tornar:

(1) “O Programa Qualidade no Serviço Público vem desenvolvendo ações na administração pública brasileira com o propósito de torná-la cada vez mais preocupada com o cidadão."

(doc \#18 - Relatório Técnico)

Vemos neste exemplo que o pronome clítico retoma o termo "administração pública" para lhe incutir uma nova característica, a saber, "preocupada com o cidadão". Nesse caso, a semântica do verbo requer um elemento compatível para receber as novas características. Vale a pena ressaltar que o verbo tornar, quando utilizado em contextos mais informais e orais de comunicação, tende a aparecer também com o objeto direto anafórico explícito por meio dos pronomes lexical ele/eles ou ela/elas.

No contexto a seguir, o verbo fazer é causativo, o que implica que o sujeito, mesmo não estando explícito, deverá causar a ação, com consequente alteração do estado do objeto, ou seja, ele deve ser responsável pelo aumento do número de "escolas primárias" que comporão a "rede". O pronome clítico retoma o núcleo "rede" tanto como objeto do verbo "fazer" quanto como sujeito do verbo "crescer":

(2) "Isso não significa o abandono da rede de escolas primárias, é evidente. Será preciso fazê-la crescer sempre." (doc \#4 - Educação) 
Vemos a seguir uma ocorrência do verbo apresentar com o clítico, o que configura um contexto de baixa frequência no corpus:

(3) “O Deputado Dr. Rosinha deu a ideia de apresentar um PDL. Ótimo, vamos apresentá-lo, mas quando será votado? No ano que vem? Temos de acertar com o Governo a preservação do piso constitucional para a saúde, de acordo com a Emenda Constitucional no 29."

(doc \#28 - Sessão do Congresso/Política)

Aqui temos a transcrição de um discurso político que faz uso do clítico como OD do verbo apresentar. No trecho, constata-se que a ausência do pronome não causaria ambiguidade devido à proximidade do sintagma nominal retomado pelo clítico e ao fato de não haver outros sintagmas em concorrência. No que diz respeito à semântica do verbo apresentar, o estado do OD não é afetado pelo verbo, havendo apenas uma transição entre 'ser desconhecido' e 'ser conhecido' pelo interlocutor. Como há baixa transitividade e consequente baixo afetamento do objeto, é bem possível que a presença do pronome se deva ao grau de formalidade do gênero textual em questão, visto que o gênero também é um fator significativo na variação dos pronomes objeto, como veremos mais adiante.

A ocorrência de ignorar com clítico também representa um contexto de baixa frequência no corpus, assim como no exemplo anterior:

(4) 'A 'fatwa' de uma autoridade religiosa é algo que um governo não pode cancelar, e o governo do Irã não pode ignorá-la ou cancelá-la." (doc \#6 - Jornalismo/Jornal)

Neste exemplo, de modo semelhante ao anterior com apresentar, o verbo "ignorar" vem acompanhado do clítico OD, apesar do baixíssimo grau de transitividade. Semanticamente ignorar é uma ação que diz respeito ao sujeito, um agente animado, não ao objeto (ignorar (...) "não conhecer, não saber", Dic. Houaiss, 2009). Nesse caso de exceção no corpus, a presença do clítico recebe influência da natureza mais formal do texto, visto tratar-se de escrita jornalística, assim como da estratégia de ênfase, expressa por meio da repetição do verbo "cancelar". Após a primeira ocorrência de "cancelar" sem o clítico, o locutor retoma as duas ações e, nesse momento, emprega os clíticos para deixar bem clara a relevância de "fatwa" em seu discurso. Sem a presença do clítico, as ações de "ignorar" e "cancelar", centradas no sujeito, ficariam em evidência, deixando a 'fatwa” em segundo plano.

Outro exemplo com o verbo ignorar reforça a relevância do contexto para a variação:

(5) "A técnica da carta-perdida consiste na colocação de cartas endereçadas e seladas em locais públicos, simulando o extravio das mesmas. A pessoa que encontra uma destas cartas pode ignorá-la, enviá-la pelo correio ou destruí-la."

(doc \#8 - Acadêmico/Artigo)

Aqui observamos o mesmo verbo em um ambiente no qual a omissão de seu objeto direto não afeta a construção do sentido por parte do interlocutor. Talvez seu emprego se deva a questões pragmático-discursivas, como o encadeamento de verbos de ação e a consequentemente necessidade de enfatizar que, apesar de se tratar de ações distintas, o objeto é o mesmo, "uma dessas cartas". É importante ressaltar a existência de regras prescritivas a serem aplicadas na produção de textos acadêmicos, que, em princípio, condicionariam a escolha dessa variante. Nesse momento, nos perguntamos se essas regras, de fato, são seguidas, mas esse seria assunto de outra pesquisa.

No último exemplo, o trecho foi extraído do mesmo documento trabalhado 
no exemplo (8). Neste, há um forte diálogo estabelecido entre o âmbito educacional e a religião institucionalizada. Dado o caráter extremamente formal dos textos litúrgicos das religiões cristãs, compreendemos que o contexto pragmático-discursivo, de certo modo, obriga a explicitação do pronome objeto. No discurso aqui apresentado, verifica-se que o pronome objeto poderia ser omitido sem qualquer prejuízo para o conteúdo semântico da frase:

(6) "É quando Pilatos diz a Cristo: "Não sabes que tenho poder para te mandar matar?" E Cristo então lhe responde: "Do alto lhe veio este poder!" / Também o educador recebeu do alto este poder de educar. E recebeu-o do Mestre, do grande Mestre, do divino Mestre." (doc \#4 - Educação)

Os resultados do levantamento de dados, com as respectivas frequências de ocorrência dos verbos, e das análises nos permitem aplicar o continuum de afetamento do objeto para a explicitação do clítico em função de OD anafórico no PB. Confirmando nossa hipótese, constatamos que, quanto maior a influência sobre o estado do objeto, maior a chance de o objeto direto estar explícito na forma de pronome clítico, assim como menos influência sobre o estado do objeto leva a uma menor chance de sua explicitação, conforme configurado no continuum abaixo (Figura 1).

Figura 1 - Continuum da presença do pronome objeto

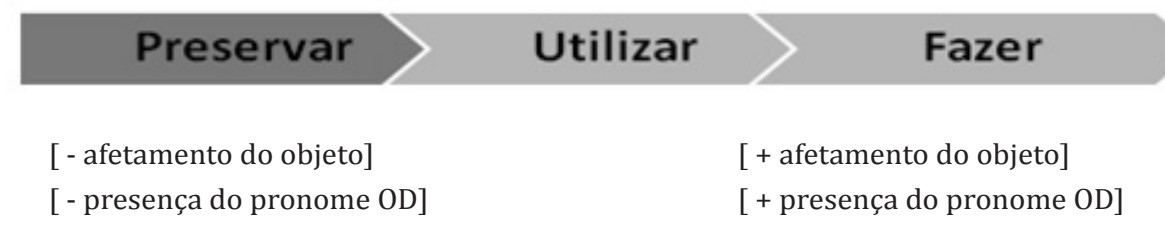

Mas nosso levantamento de dados e nossas análises revelaram, também, que, mesmo com um menor grau de afetamento do objeto, existe a possibilidade, ainda que pequena, de que certos verbos sejam combinados com um clítico manifesto. Nesses casos, a força maior que impele o emprego do clítico está no grau de formalidade do gênero textual, assunto a ser discutido a seguir.

\subsection{0 gênero textual}

Em consonância com Marcuschi $(2003 ; 2008)$, entendemos o gênero textual como uma entidade sociocomunicativa, vinculada às interações sociais e às práticas cotidianas, representando a materialização de textos orais e escritos. Por ser o elemento estruturante das relações comunicativas, o gênero textual é fator relevante em diversos fenômenos de variação linguística, e em nossa pesquisa não seria diferente.

Assim, em um segundo momento de nossa pesquisa, após termos percebido que a semântica lexical é fator de grande relevância, mas que ainda havia casos a serem explicados, nos perguntamos sobre o papel do contexto de interação na determinação de qual variante seria utilizada como retomada anafórica no discurso.

Essa segunda análise nos levou a obter novas perspectivas do problema de pesquisa com o qual este artigo trabalha, observando que, além de uma motivação semântica interna do verbo, existe uma motivação pragmáticodiscursiva externa à sintaxe, que faz com que a forma mude para se adequar aos contextos discursivos em função da natureza do gênero, como vimos nos exemplos analisados no item anterior.

Nos dados coletados no corpus Brasileiro, as ocorrências de clíticos se restringem a textos de cunho acadêmico, que consistem em teses, dissertações e artigos, ou institucional, como ofícios públicos do Diário Oficial da União e pareceres técnicos e jurídicos de órgãos oficiais públicos. Como 
a escrita formal é de estilística mais monitorada (BAGNO, 2007, p. 45), é bem provável que os autores façam uso dessas estratégias para se adequar à norma-padrão de prestígio da língua portuguesa, prescrita nas gramáticas normativas.

No caso específico dos verbos de baixa transitividade, temos a seguinte tabela:

Tabela 3 - Verbos de baixa transitividade e gêneros textuais formais

\begin{tabular}{|c|c|}
\hline Verbo & Gênero textual \\
\hline Apresentar & $\begin{array}{l}\text { a. Texto Acadêmico } \\
\text { (Artigos, Tesese e Dissertaçõos) } \\
\text { b. Texto Jornalístico } \\
\text { c. Sessões Políticas do Congresso }\end{array}$ \\
\hline Ignorar & $\begin{array}{l}\text { a. Texto Acadêmico } \\
\text { (Artigos, Teses e Dissertações) } \\
\text { b. Texto Jornalístico } \\
\text { c. Sessões Políticas do Congresso }\end{array}$ \\
\hline Preservar & $\begin{array}{l}\text { a. Texto Acadêmico } \\
\text { (Artigos, Teses e Dissertações) } \\
\text { b. Texto Jornalístico } \\
\text { c; Sessões Políticas do Congresso }\end{array}$ \\
\hline Receber & $\begin{array}{l}\text { a. Texto Acadêmico } \\
\text { (Artigos, Teses e Dissertações) } \\
\text { b. Texto Jornalístico } \\
\text { c. Sessões Políticas do Congresso }\end{array}$ \\
\hline
\end{tabular}

Conforme revelado (ver Tabela 3), os gêneros em que são empregados os pronomes OD são exatamente os mesmos. Trata-se de textos escritos e transcrições de textos orais bastante formais, restritos a determinadas situações sociais e ligados a contextos profissionais específicos. À exceção dos textos jornalísticos, que têm maior veiculação, mesmo que nem sempre sejam lidos e compreendidos por grande parte da população brasileira, pois se utilizam muitas vezes de linguagem técnica, os outros gêneros são direcionados a um público-alvo individualizado e de difícil acesso aos cidadãos.

$O$ fato de o gênero textual de natureza formal condicionar a presença do clítico objeto direto nos leva à hipótese de que a explicitação do objeto em retomada anafórica tem se tornado cada vez mais artificial na tipologia do $\mathrm{PB}$, já que domínios discursivos dos gêneros textuais mais formais pedem um maior monitoramento da forma. É mais natural para os falantes de PB omitir o objeto direto como estratégia de retomada anafórica do que utilizar um pronome ou a repetição do sintagma nominal para o mesmo processo, conforme demonstraram Bagno (2013) e Duarte (1986), em corpora baseados em textos orais.

Podemos, então, sistematizar os traços pragmático-discursivos que influenciam a explicitação do pronome objeto em um espectro, com dois polos extremos, relacionados ao grau de formalidade do contexto de veiculação:

Figura 2 - Formalidade do gênero e uso dos pronomes objetos

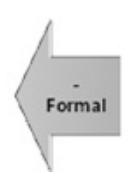

[ - presença do pronome OD]

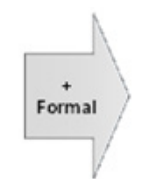

[ + presença do pronome OD $]$

Em contexto de maior formalidade do texto, o falante tende à explicitação do pronome objeto. Vimos em exemplos anteriores que os clíticos podem ser empregados de modo a adequar o texto aos padrões normatizados para os contextos formais. $\mathrm{O}$ contexto pragmático-discursivo é relevante na seleção das variantes, e a escolha de uma estratégia pode transmitir informações de cunho social como nível de escolaridade, poder aquisitivo e até mesmo grau de intimidade para com o interlocutor. 


\section{Considerações finais}

Em nossa pesquisa, nos propusemos a analisar contextos de ocorrência dos clíticos de 3a pessoa $o(s), n o(s), l o(s)$ e $a(s), n a(s), l a(s)$, que exercem a função de objeto direto. Conforme comprovado por autores como Tarallo (1993), Duarte (1986) e Bagno (2013), a retomada anafórica é um fenômeno em variação no português brasileiro. As estratégias possíveis incluem, além do emprego de clíticos, o uso dos pronomes lexicais ele(s)/ela(s), de um sintagma nominal ou a possibilidade de deixar a posição vazia, estratégia esta denominada pronome nulo.

Os dados coletados no corpus Brasileiro demonstraram que o afetamento do objeto é um fator condicionante na explicitação dos clíticos OD em retomada anafórica. As análises foram feitas com base na frequência de ocorrências de verbos com a presença de clíticos e em sua associação com a semântica lexical do verbo. Verbos como fazer e tornar, por exemplo, apresentam frequência alta de ocorrência com clíticos OD e afetam o estado do objeto.

Com verbos cujo grau de transitividade é baixo, como apresentar, ignorar, preservar e receber, a frequência com a presença de clíticos é baixa. Nesses casos, constatou-se que o fator significativo é o grau de formalidade do gênero textual. Assim, os exemplos com esses verbos foram extraídos de textos acadêmicos, como artigos, teses e dissertações, jornalísticos e de sessões políticas do Congresso, todos gêneros textuais de natureza formal.

A princípio, as porcentagens obtidas por este estudo podem parecer pequenas se comparadas com a quantidade de informações disponíveis no banco de dados do corpus analisado (mais de 1,1 bilhão de entradas). Entretanto, ao compararmos a quantidade de vezes com as quais os clíticos são usados nos dados levantados por Duarte (1986) e Bagno (2013), é possível observar que as porcentagens de ocorrências são bem parecidas, o que demonstra que essa é uma tendência real do Português Brasileiro.

A Linguística de Corpus se revelou uma ferramenta fundamental para a composição deste artigo, principalmente porque permite análises quantitativas e qualitativas. Observar o número de ocorrências nos contextos em que elas ocorrem nos permitiu traçar um paralelo entre forma e função, de modo que o resultado da análise aqui apresentada resultou numa consideração semântica das diferentes formas existentes para explicitação do pronome objeto direto no PB.

Entretanto, é preciso também reconhecer os limites da metodologia aplicada. Mesmo com a tecnologia hoje disponível, não pudemos mapear outras estratégias variantes da retomada anafórica de $3 \underline{a}$ pessoa. Isso porque o reconhecimento de vazios lexicais como elementos gramaticais é difícil de ser computadorizado, sendo necessária uma análise manual dos dados, o que, no caso do corpus Brasileiro, é inviável, devido ao grande volume de ocorrências. Do mesmo modo, uma análise extensiva do uso de pronomes pessoais retos de $3^{\underline{a}}$ pessoa (ex.: Ele, Ela, Eles, Elas) é uma tarefa bastante complexa, já que essas formas pronominais também exercem função de sujeito.

Por fim, este estudo trouxe consigo um olhar funcionalista sobre a variação, de modo a não apenas demonstrar estatisticamente as formas variantes, mas principalmente buscar as funções relacionadas com cada forma variante. Do mesmo modo, foi possível compreendermos os contextos em que essas funções semânticas e pragmáticas alteram as formas da língua.

\section{Referências}

BAGNO, Marcos. Dramática da Língua Portuguesa. São Paulo: Loyola, 2000. Português ou Brasileiro? Um convite à pesquisa. São Paulo: Parábola, 2001. 
Nada na língua é por acaso: por uma pedagogia da variação linguística. São Paulo: Parábola, 2007.

Gramática Pedagógica do Português Brasileiro. São Paulo: Parábola, 2013.

BORTONI-RICARDO, Stella Maris. Manual de sociolinguística. São Paulo: Contexto, 2014.

BORBA, Francisco da Silva. Dicionário gramatical de verbos. 2. ed. São Paulo: Editora da Unesp, 1990.

BYBEE, Joan. Morphology: a Study of the Relation between Meaning and Form. Amsterdam/Philadelphia: JBPC, 1985. https://doi.org/10.1075/tsl.9

CUNHA, Maria Angélica; SOUZA, Maria. Transitividade e seus contextos de uso. Rio de Janeiro: Lucerna, 2011.

DIK, Simon; HENGEVELD, Kees. The Theory of Functional Grammar - Part 1: The structure of the clause. Berlim: de Gruyter, 1997.

DUARTE, Maria Eugênia. Variação e sintaxe: clítico acusativo, pronome lexical e categoria vazia no Português do Brasil. Dissertação (Mestrado em Letras) - Pontifícia Universidade Católica de São Paulo, 1986.

FREGE, Gottlob. Lógica e filosofia da linguagem. São Paulo: Cultrix, 1978.

HOUAISS, A. Dicionário eletrônico Houaiss da língua portuguesa 3.0. Rio de Janeiro: Objetiva, 2009.

HOPPER, Paul; THOMPSON, Sandra. Transitivity in Grammar and Discourse. Language, v. 56, n. 2, p. 251-299, jun. 1980. https://doi.org/10.1353/lan.1980.0017

ILARI, Rodolfo. Introdução à semântica. São Paulo: Contexto. 2001.

KOCH, Ingedore. O texto e a construção dos sentidos. São Paulo: Contexto, 1997.

KUČERA, Henry; FRANCIS, W. Nelson. Computational Analysis of Present-Day American English. Providence: Brown University Press, 1967.

MARCUSCHI, Luiz Antonio. Gêneros textuais: definição e funcionalidade. In: DIONISIO, Angela P.; Machado, Anna R.; BEZERRA, Maria A. Gêneros textuais \& Ensino. Rio de Janeiro: Lucerna, 2003

. Produção textual, análise de gêneros e compreensão. São Paulo: Parábola Editorial, 2008.

PAYNE, Tom. Describing Morphosyntax: A Guide for Field Linguistics. Cambridge: CUP, 1997.
ROSCH, Eleanor. Natural categories, Cognitive Psychology, v. 4, p. 328-350, maio 1973.

Cognitive Representations of Semantic Categories, Journal of Experimental Psychology: General, v. 104, n. 3, p. 192-233, set. 1975. https://doi.org/10.1037/ 0096-3445.104.3.192

SARDINHA, Tony. Linguística de corpus. Barueri, São Paulo: Manole, 2004.

TAGNIN, Stella. O jeito que a gente diz. São Paulo: Disal, 2013.

TARALLO, Fernando. A pesquisa sociolinguística. 2. ed. São Paulo: Ática, 1986.

Diagnosticando uma gramática brasileira: o português d'aquém e d'além-mar ao final do século XIX. In: ROBERTS, Ian; KATO, Mary (Org.). Português Brasileiro: uma viagem diacrônica. Campinas: Ed. da UNICAMP, 1993. p. 69-106.

TRAVAGLIA, Luiz Carlos. Continuidades de tipos de verbos e situações de formas e categorias verbais e tipos de texto. Caderno de Estudos Linguísticos, Campinas, n. 44, p. 183-197, jan.-jun. 2003.

Um estudo textual-discursivo do verbo no português do Brasil. Tese (Doutorado) Universidade de Campinas (UNICAMP), 1991.

Recebido em 28/05/2016.

Aceito em 14/02/2017. 